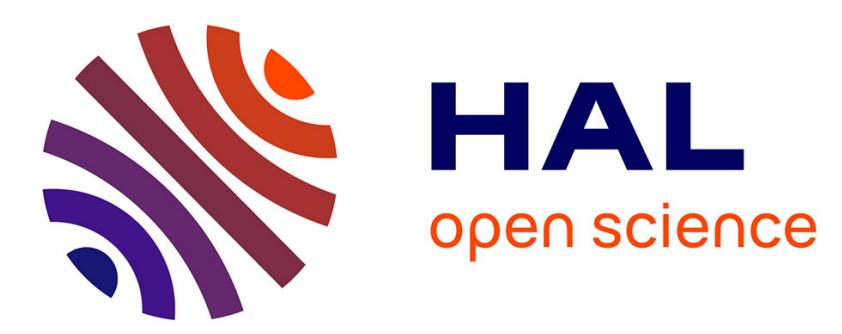

\title{
Porosity redistribution enhanced by strain localization in crystal-rich magmas
}

Mickaël Laumonier, Laurent Arbaret, Alain Burgisser, Rémi Champallier

\section{To cite this version:}

Mickaël Laumonier, Laurent Arbaret, Alain Burgisser, Rémi Champallier. Porosity redistribution enhanced by strain localization in crystal-rich magmas. Geology, 2011, 39 (8), pp.715-718. 10.1130/G31803.1 . insu-00598303

\section{HAL Id: insu-00598303 https://hal-insu.archives-ouvertes.fr/insu-00598303}

Submitted on 10 Jun 2011

HAL is a multi-disciplinary open access archive for the deposit and dissemination of scientific research documents, whether they are published or not. The documents may come from teaching and research institutions in France or abroad, or from public or private research centers.
L'archive ouverte pluridisciplinaire HAL, est destinée au dépôt et à la diffusion de documents scientifiques de niveau recherche, publiés ou non, émanant des établissements d'enseignement et de recherche français ou étrangers, des laboratoires publics ou privés. 


\title{
Porosity redistribution enhanced by strain localization in crystal-
}

\section{rich magmas}

\author{
Mickael Laumonier ${ }^{1 *}$, L. Arbaret ${ }^{1}$, A. Burgisser ${ }^{1}$, R. Champallier ${ }^{1}$. \\ ${ }^{1}$ CNRS Institut des Sciences de la Terre d'Orléans, UMR 6113, université d'Orléans, Campus \\ géosciences, 1 A rue de la férolerie, 45071 Orléans cedex 2, France.
}

\begin{abstract}
Magma degassing, characterized by changes in permeability and porosity distribution, has a crucial control on the style of eruption. During ascent, magma might develop large porosities and crystallise while it is subjected to shear. Shear, in turn, enhances complex fabrics that result from the reorganization of the different phases (crystals, gas, melt). Such fabrics have not yet been evaluated experimentally on a 3-phase system. We performed torsion experiments on a synthetic crystal-rich hydrous magma at subsolidus conditions with 11 vol.\% porosity to establish a link between strain partitioning and porosity redistribution. Crystals induce non-Newtonian deformation, resulting in localization of the shear strain. 3-D microtomography and 2-D Scanning Electron Microprobe (SEM) imaging show gas accumulation in local microstructures caused by shearinduced crystal fabric. Our data show that strain localization is a mechanism that could enable magma degassing at very low vesicularity.
\end{abstract}

\section{INTRODUCTION}

The eruption style of hydrous magmas is mainly controlled by their ability to degas (e.g. Eichelberger et al., 1986). During magma transfer to the surface, the decompression causes bubble exsolution. If these bubbles remain in the magma, the over-compressed gas can exceed the tensile strength of magma (Zhang, 1999), causing fragmentation that may lead to catastrophic explosive eruption (Villemant and Boudon, 1998; Sparks, 2003). The most efficient mechanism for the gas to escape the magma is the creation of an interconnected bubble network (Eichelberger et al., 1986). 
Shearing is an efficient process to stretch and coalesce bubbles, which can start at 20 to $30 \%$ of porosity (Okumura et al. 2008). A connected bubble network can be generated in a sheared crystalfree rhyolite with 30 vol\% of bubbles (Okumura et al. 2009) by a modest shear strain $(\gamma=8)$. In natural felsic pumices, Wright and Weinberg (2009) recognised strain localization at microscopic scale. The three phases composing magma (bubbles, crystals and melt) can be organized by strain localization and associated structures, and conversely. Such structural evolutions rule the mechanical behaviour of the magmas and influence their transfer to the surface (Saar et al. 2001; Picard, 2009). The rheological properties of crystal-bearing magmas have been the subject of several experimental studies (Caricchi et al. 2007; Champallier et al., 2008; Cordonnier et al., 2009) and are closely linked to microstructures development (Arbaret et al., 2007; Lavallée et al., 2008; Picard 2009). Picard (2009) experimentally reproduced S/C' type textures (Berthé et al. 1979) similar to those encountered in natural, felsic, crystal-rich magmas (Smith, 2002). Many experimental and numerical studies focused on the behaviour of two-phase systems (bubble-melt or crystal-melt), which left out the potential coupled effects of the crystal network on the evolution of the bubble network.

In order to establish a link between strain-induced microstructures and magma outgassing, we experimentally synthesized and deformed three phase felsic magma at subsolidus conditions. The relationship between strain localization structures and bubble network geometry has been evidenced by 3-D microtomography and 2-D Scanning Electron Microprobe (SEM) imaging.

\section{SUMMARY OF EXPERIMENTAL METHODS}

A synthetic haplotonalitic suspension composed of plagioclases (crystal fraction $\Phi c=0.52$, calculated on bubble-free assemblage $)$, hydrated melt $(\Phi \mathrm{m}=0.48)$ and water gas bubbles $(\Phi g=$ 0.11) was deformed by torsion in a Paterson gas-medium apparatus (ASI Instruments, Paterson and Olgaard, 2000) at pressure and temperature of $200 \mathrm{MPa}$ and $600^{\circ} \mathrm{C}$, respectively (see Champallier et al. 2008). Strain rate $\gamma_{\mathrm{r}}$ ranged from $3 \cdot 10^{-5}$ to $1 \cdot 10^{-3} \mathrm{~s}^{-1}$, and bulk finite strains reached $\gamma_{\text {bulk }}=1.3$. 
Before and after experiments, the size, proportion and shape-preferred orientation of the bubbles have been characterized in 3D by microtomographic imaging and 2D by SEM imaging. The starting material has an isotropic distribution of crystals and bubbles, determined by SPO2003 software (Launeau, 2004). Crystals are $25 \mu \mathrm{m}$ long plagioclases with a shape ration of 2.5 (see supplementary data for more information). Water content in the saturated melt is around $6.5 \mathrm{wt} \%$.

\section{STRAIN LOCALISED STRUCTURES}

Shearing causes a pervasive deformation that affects the entire sample and a localisation of strain that creates normal bands, synthetic in relation to the sense of shear with varied local strain $\gamma_{\text {loc }}$ visible on the jacket (Fig. 1). We identified three types of localized, planar structures (Fig. 2A). Types 1 and 2 consist in normal bands, synthetic with respect to the direction of shear, and along which voids accumulate. We distinguish bubbles from voids, which are gas-filled cavities that result from gas phase reorganization. Bubbles are local exsolution of volatiles from the melt. Type 1, roughly $400 \mu \mathrm{m}$ thick, dips $\sim 22^{\circ}$. These shear bands consist in a large cavity that forms a continuous open space bounded by two bubble-free zones, which are each up to $200 \mu \mathrm{m}$ thick (Fig. 2B). Type 2 shear bands dip $\sim 60^{\circ}$ and join Type 1 bands (Fig. $\left.2 \mathrm{~A}\right)$. They are thinner $(<150 \mu \mathrm{m})$ than Type 1 bands and also feature zones where bubbles are concentrated. In some areas, such as in the vicinity of Type 1 bands, they seem dense. The Type 3 structure is composed of bubble-free bands (Fig. 2A) that fluctuate from flat-lying to $-6^{\circ}$ clockwise with respect to shear direction. They are synthetic reverse, therefore mainly transpressive. All planar structures are connected lengthwise. 3-D imaging shows that, overall, these three types of structures form an anastomosing pattern of shear bands along which the porosity is clearly redistributed. Outside of these structures, vesicles are slightly oriented by the low pervasive deformation (Fig. A, supplementary data).

In order to get more detailed information about the development of the structures, 2-D SEM images were selected in areas having undergone various local strains $\gamma_{\text {loc }}$ (Fig. 3). At low strain $\left(\gamma_{\text {loc }} \approx 0.4\right.$, 
Fig. 3B), the gas voids cover a cumulative surface identical to that outside strained structures (Fig. 3A) but with a smaller individual size ( $53 \mu \mathrm{m}^{2}$ vs. $110 \mu \mathrm{m}^{2}$ outside). Whereas most of the surface is composed of large voids, a population of numerous little voids develops. It is difficult to determine the nature of this new population from post-experiment observations. Isobaric quench excludes that bubbles form at the end of experiment when the temperature decreases. The small voids might be issued from the break up of large bubbles. They could also possibly come from the dehydration of the melt due to local underpressure in transtensive zones. At $\gamma_{\text {loc }} \approx 1.7$, the gas phase consists only of small voids $\left(\sim 35 \mu \mathrm{m}^{2}\right)$ preferentially oriented (void long axis at $28^{\circ}$ below the shear direction, Fig. 3C). The porosity $(\sim 16 \%)$ is larger than in zones that suffered lower strain. This suggests that the initial bubbles were not only dismantled by crystal displacement, but also that they migrated from adjacent regions subjected to lower strains. At $\gamma_{\text {loc }} \approx 9.4$, the gas phase covers around $29 \%$ of the surface and voids aggregate in a large cavity oriented around $+25^{\circ}$ with the plane of shear (Fig. 3D). These transtensive zones typify Type 1 in 3-D observations.

In addition to these transtensive zones, different sets of transpressive, slightly tilted bands were generated by shear (Fig. 3E). These bands feature cataclasis (fragmented crystals), shape fabric (oriented crystals in a direction parallel to the shear band) and only some small voids $\left(\sim 6 \mu \mathrm{m}^{2}\right)$ that cover less than $4 \%$ of the surface. The bubbles in the vicinity of the bands suffered little deformation as they remain nearly equant, contrary to sheared zones (e.g. fig. 3C). The cataclased shear bands are Y-like bands, as described by Bauer et al. (2000; references therein). Crystal cataclasis establishes the transition from ductile S/C geometry to brittle behaviour where structures match Riedel system characterised by R shears associated with P compressive shears (Riedel 1929) which crosscut the pervasive fabric to allow for volume conservation. In addition, the bands of Type 2, locally bubble-free, fit R' fracture orientations (Riedel, 1929). This is consistent with our observations showing that all these bands are connected lengthwise to form a continuous anastomosed shear system. 
Observations made in zones that suffered different finite local strains evidence the link between strain localization and gas phase organization. Along normal shear zones, initial bubbles are dislocated and then accumulate in large voids connecting the gas phase $\left(\gamma_{\text {loc }} \approx 9.4\right.$; fig. 3D). On the contrary, bubbles tend to disappear in reverse shear bands where transpressive conditions prevail.

\section{MAGMA RHEOLOGY AND POROSITY SEGREGATION}

The synthetic suspension was designed to reproduce natural magmas in terms of chemical composition, relative phase proportions and textural organisation. Experimental subsolidus temperature, pressure and applied strain rates are consistent with conditions expected along the margins of volcanic conduits. Unlike natural systems, however, the experiments occurred over a limited range of finite strain because runs were stopped when strain localisation became so important that it caused a significant drop in the stress we measured, with potential risk for the jacket integrity. Although we evidenced porosity concentration along transtensional shear zones that lead to open fractures, associated measures of local and global permeabilities are beyond the scope of the present work.

In dilute crystal suspensions, the shear flow is accommodated by crystal rotation, which leads to pervasive fabrics with a maximum density direction almost parallel to the shear direction (Arbaret et al., 2007). At a critical crystal fraction, $\Phi^{*}$, shear flow is prevented by the formation of a crystal network. The value of $\Phi^{*}$ depends on both crystal fraction and shape; the higher the crystal aspect ratio, the lower the critical crystal fraction is (Saar et al., 2001). Our plagioc lase suspension has a crystal fraction $(\Phi c=0.52)$ that exceeds the $\Phi^{*}$ expected for the corresponding plagioclase shape $\left(\Phi^{*<38 \%}\right.$; Picard, 2009). This implies the suspension has a non-Newtonian behaviour (e.g. Caricchi et al., 2007; Lavallée et al., 2008; Picard, 2009). Whereas the strain rate has been evidenced to be a possible cause of the brittle-ductile transition (Lavallée et al., 2008), our experiment shows the development of both brittle and ductile structures while the global stress conditions are constant. Locally, however, the strain increases in shear bands, resulting in an increase of the strain rate. As 
evoked by Caricchi et al. (2008), the presence of bubbles favours strain localization, locally reducing stress. The bulk deformation over the entire sample is complex, in spite of a simple mechanical stress-strain curve from rheological measurements (Supplementary data B). The stable strength measured is the sum of several different comportments resulting in various structure developments. The presence of discrete cataclasis means that the crystal suspension locally behaved in a brittle fashion.Outside of the bands, the strain marker (Fig. 1) and pervasive fabrics indicate a pseudo-plastic behaviour (Champallier et al., 2008). The mechanical transition, as revealed by these two different behaviours, has commonly been observed in ash flow tuffs (Best and Christiansen, 1997) and reproduced experimentally (Picard, 2009). The existence of this transition has also been inferred from similar natural observations in tuffisites (Tuffen et al., 2003), in a rhyolite flow (Smith, 1996), and in a dacitic lava dome (Smith et al., 2001). Our results show that, even above the solidus and for relatively low bulk strain rates, crystals are largely responsible for strain localization, which can increase the strain rate enough to cause local brittle cataclasis.

The redistribution of the porosity depends on the orientation and the kinematics of the bands, which is essentially controlled by crystal motion. Large voids are exclusively observed along transtensive bands whereas transpressive bands are almost gas-free (Fig. 3). A possible mechanism controlling gas segregation is the relative stress induced by the deformation-induced localizations. Gas moves away from local compressed domains to less stressed surroundings, mostly because the gas phase itself is mobile within the connected voids. Although not observed in our experiments, it can freely flow out of transpressive P shear bands and partly along R' fractures, which causes porosity to vanish. The localization of the deformation enhances such transfer by displacing the gas phase from transpressive shear bands to other transtensive structures. In the transtensive R-like bands, bubbles concentrate and fill the band, increasing the porosity locally. The melt does not seem to be segregated from the crystals, at least over the strain imposed experimentally. 
Strain localisation has also been recognized in natural, felsic crystal-poor pumice by Wright and Weinberg (2009). Despite high porosity (> 60\%) and high inferred strain, they do not evidence bubble coalescence. In crystal-free magmas, Okumura et al. (2009) demonstrate that the same result can be achieved with only 30 vol $\%$ of gas if the deformation reaches $\gamma=8$. Although our study reveals the coalescence of bubbles by strain localization at low bulk strain and low strain rates in crystal-rich magmas, it does not imply individual bubble elongation as proposed by Okumura et al. (2009). We conclude that highly crystallized magmas are able to redistribute the porosity in shear bands by strain localization and reorganization of the crystal assemblage.

\section{IMPLICATION FOR SHEAR BANDING AND MAGMA OUTGASSING}

Local shear structures are hardly observable in place at depth. However, indirect evidences in eruptive products suggest the common development of such structures at high pressure. In the products from Sycamore Canyon, Arizona, Seaman et al. (2009) recognised layers with different water contents. They attributed this layering to a repeated fracturing which enhanced magma outgassing because of depressurisation in the fragmented zones. Another example of tuffisite from Mule Creek, New Mexico, presents heterogeneous permeability and may be the result of a sheared magma (Stasiuk et al., 1996). Rust et al. (2004) observed host fragments mixed with the erupted magma that they interpreted as the consequence of the simultaneous fragmentation of the ascending magma and the conduit walls. Banded low-porosity textures in the product of the Vulcanian eruptions of the Soufrière Hills, Montserrat, suggests that the bands were formed along the conduit wall (Kennedy et al., 2005). Our own sampling of the 1997 Vulcanian products at Montserrat (Burgisser et al., 2010) allows us to complete the possibility that the banded low porosity textures were formed during a localised sheared deformation within the magma prior to eruption. Along volcanic conduit walls, such a network is supposed to connect to fractures developed along the

conduit margins (Fig. 4). Through torsion experiments of crystal-rich magma, we demonstrated that low shear strains trigger gas segregation from randomly distributed large bubbles to a connected, 
porous Riedel network. We thus expect the connected network to efficiently segregate the exsolved water from the adjacent hydrous melt and favour its migration through open fractures, thereby causing a local and heterogeneous outgassing of the magmatic plug (Fig. 4).

Finally, our experiments evidence the significant control that shear strain localization exerts on porosity segregation to form open and therefore permeable fractures. Our results show that crystalrich magma outgassing along conduit margins can occur at much lower porosity and strain than expected from crystal-free bubbly melts (Okumura et al., 2009). Since crystal-rich situations prevail in shallow regions of conduits, where slow ascent rates promote microlite crystallisation, our experiments provide a likely mechanism of fast, shallow outgassing in highly viscous, three-phase magmas.

\section{ACKNOWLEDGEMENTS}

The authors are grateful to S. Okumura and Y. Lavallée for their constructive reviews. We benefited from discussions with Michel Pichavant, Luca Caricchi and David Picard. Olivier Rouer helped us to use the SEM.The project was partly funded by the Agence Nationale de la Recherche (ANR-EXPLANT, Contract No ANR-05-CATT-003 to C. Martel) and by the ERC grant 202844 under the European FP7 attributed to A. Burgisser.

\section{REFERENCES CITED}

Arbaret, L., Bystricky, M., Champallier, R., 2007, Microstructures and rheology of hydrous synthetic magmatic suspensions deformed in torsion at high pressure, Journal of Geophysical Research 112, B10208.

Bauer, P., Palm, S. and Handy, M.R., 2000, Strain localization and fluid pathways in mylonite: Inferences from in situ deformation of a water-bearing quartz analogue (norcamphor), Tectonophysics 320, 141-165. 
Berthé, D., Choukroune, P. and Jégouzo, P., 1979, Orthogneiss, mylonite and non-coaxial deformation of granite: the example of the South Armorican Shear Zone, Journal of Structural Geology 1, 31-42,.

Best, M.G., Christiansen, E.H., 1997, Origin of broken phenocryst in ash-flow tuffs, Geological Society of America 109, 63-73.

Burgisser, A., Poussineau, S., Arbaret, L., Druitt, T., Giachetti, T., Bourdier, J.L., 2010, Preexplosive conduit conditions of the 1997 Vulcanian explosions at Soufrière Hills Volcano, Montserrat: I. Pressure and vesicularity distributions, Journal of Volcanology and Geothermal Research 194, 27-41.

Caricchi, L., Burlini, L., Ulmer, P., Gerya, T., Vassalli, M., Papale, P., 2007, Non-Newtonian rheology of crystal-bearing magmas and implications for magma ascent dynamics. Earth and Planetary Science Letter 264, 402-419.

Caricchi, L., Giordano D., Burlini, L., Ulmer, P., Romano C., 2008, Rheological properties of magma from the 1538 eruption of Monte Nuovo (Phlegrean Fields, Italy): An experimental study, Chemical Geology 256, 158-171.

Champallier, R., Bystricky, M. and Arbaret, L., 2008, Experimental investigation of magma rheology at 300MPa: From pure hydrous melt to 75 vol. \% of crystals. Earth and Planetary Science Letter 267, 571-583.

Cordonnier, B., Hess, K.-U., Lavallée, Y., Dingwell, D.B., 2009, Rheological properties of dome lavas: Case study of Unzen volcano. Earth and Planetary Science Letter 279, 263-272.

Eichelberger, J.C., Carrigan, C.R., Westrich, H.R., Price, R.H., 1986, Non-explosive silicic volcanism. Nature 323, 598-602.

Kennedy, B., Spieler, O., Scheu, B., Kueppers, U., Tadeucci, J., 2005, Conduit implosion during Vulcanian eruptions, Geology 33, 581-584.

Launeau, P., 2004, Mise en évidence des écoulements magmatiques par analyse d'image 2-D des distributions 3-D d'Orientations Préférentielles de Forme, Bull. Soc. Géol. Fr. 175, 331-350. 
(« Magmatic flows brought to light by 2-D image analysis of the distribution of 3-D Shape Preferred Orientation »)

Lavallée, Y., Meredith, P.G., Dingwell, D.B., Hess, K.-U., Wassermann, J., Cordonnier, B., Gerik, A., Kruhl, J.H., 2008, Seismogenic lavas and explosive eruption forecasting, Nature 453 (7194), 507-510.

Okumura, S., Nakamura, M., Tsuchiyama, A., Nakano, T., Uesugi, K., 2008, Evolution of bubble microstructure in sheared rhyolite: formation of a channel-like bubble network. Journal of Geophysical Research 113, B07208.

Okuruma, S., Nakamura, M., Takeuchi, S., Tsuchiyama, A., Nakano, T., Uesugi, K., 2009, Magma deformation may induce non-explosive volcanism via degassing through bubble networks, Earth and Planetary Science Letter 281, 267-274.

Paterson, M., Olgaard, D., 2000, Rock deformation tests to large shear stress in torsion, Journal of Structural Geology 22, 1341-1358.

Picard, D., 2009, HP-HT deformation of silicic magmas: experimental constrains on the structural evolution and the rheological threshold at middle and high cristallinities, [Ph.D. thesis]: University of Orléans, $333 \mathrm{p}$.

Riedel, W., 1929, Zur Mechanik Geologischer Brucherscheinungen. Zentral-blatt fur Mineralogie, Geologie und Paleontologie B, 354-368.

Rust, A.C., Cashman, K.V., Wallace, P.J., 2004, Magma degassing buffered by vapour flow through brecciated conduit margins, Geology 32, 349-352.

Saar, M.O., Manga, M., Cashman, K.V. and Fremouw, S., 2001, Numerical models of the onset of yield streggh in crystal-melt suspensions, Earth and Planetary Science Letters 187, 367-379. Seaman, S.J., Dyar, M.D., Marinkovic, N., 2009, The effects of heterogeneity in magma water concentration on the development of flow banding and spherulites in rhyolitic lava, Jouranl of Volcanology and Geothermal Research 183, 157-169.

Smith, J.V., 1996, Ductile-brittle transition structures in the basal shear zone of a rhyolite lava flow, eastern Australia. Journal of Volcanology and Geothermal Research 72, 217-223.

Smith, J.V., Miyake, Y., Oikawa, T., 2001, Interpretation of porosity in dacite lava domes as ductile-brittle failure textures, Journal of Volcanology and Geothermal Research 112, 25-35. 
Smith, J.V., 2002, Structural analysis of flow-related textures in lavas, Earth-Science Reviews 57, 279-297.

Sparks, R., 2003, Forecasting volcanic eruptions, Earth and Planetary Science Letter 210, 1-15.

Stasiuk, M.V., Barclay, J., Carroll, M.R., Jaupart, C., Ratté, J.C., Sparks, R.S.J., Tait, S.R., 1996. Degassing during magma ascent in the Mule Creek vent (USA), Bulletin of Volcanology 58, 117-130.

Tuffen H., Dingwell, D.B., Pinkerton, H., 2003, Repeated fracture and healing of silicic magma generate flow banding and earthquakes, Geology 31, 1089-1092.

Villemant, B., Boudon, G., 1998, Transition from dome-forming to plinian eruptive styles controlled by $\mathrm{H} 2 \mathrm{O}$ and $\mathrm{Cl}$ degassing, Nature 392, 65-69.

Wright, H., Weinberg, R., 2009, Strain localization in vesicular magma: Implications for rheology and fragmentation, Geology 37, 1023-1026.

Zhang, Y. (1999) A criterion for the fragmentation of bubbly magma based on brittle failure theory, Nature, v.402, p.648-650. 


\section{FIGURE CAPTIONS}

Figure 1. External appearance of the sample in its copper jacket after torsion experiment. The sample is situated between pistons and its extent is shown by the black line on the left of the picture. One of the strain markers is underlined in white to point out the different types of deformation affecting the sample. They attest shear bands are synthetic to the bulk shear sense. Numbers correspond to local strain of pervasive (italic) and localized (standard font) deformation. Some microscopic observations we used come from this side of the sample and are located by black rectangles.

Figure 2. 3-D image from microtomographic analysis. A) Column showing the gas phases as shade of grey, which highlights the 3 types of shear bands. Crystals and melt are not separated and are transparent. B) Zoom of the main shear band, which is surrounded by bubble-free areas that suggests strong vesicle rearrangement.

Figure 3. (A-D) SEM pictures showing bubble fabrics at 4 different local strains. Gas voids are black, crystals are light grey, and melt is medium grey. Rose diagrams plot the orientation of the voids. $\Phi g$ means the porosity, and $s$. means the average size of the voids. E) SEM picture with crystals colored according to their orientation. A flat lying shear band (between dotted lines) shows crystal breackage and a preferred orientation of crystals. The scale and sense of shear is common for all pictures.

Figure 4. Cartoon depicting the possible natural context where shear develops along the walls of a volcanic conduit (left), and the experimental structures observed and their relation to magma degassing (centre) and natural products from the 1997 Vulcanian eruption of Soufrière Hills, Montserrat, that feature the structures observed in the experiments (right). See text for discussion. 


\section{PP121 $-\gamma$ bulk $=1.3$}

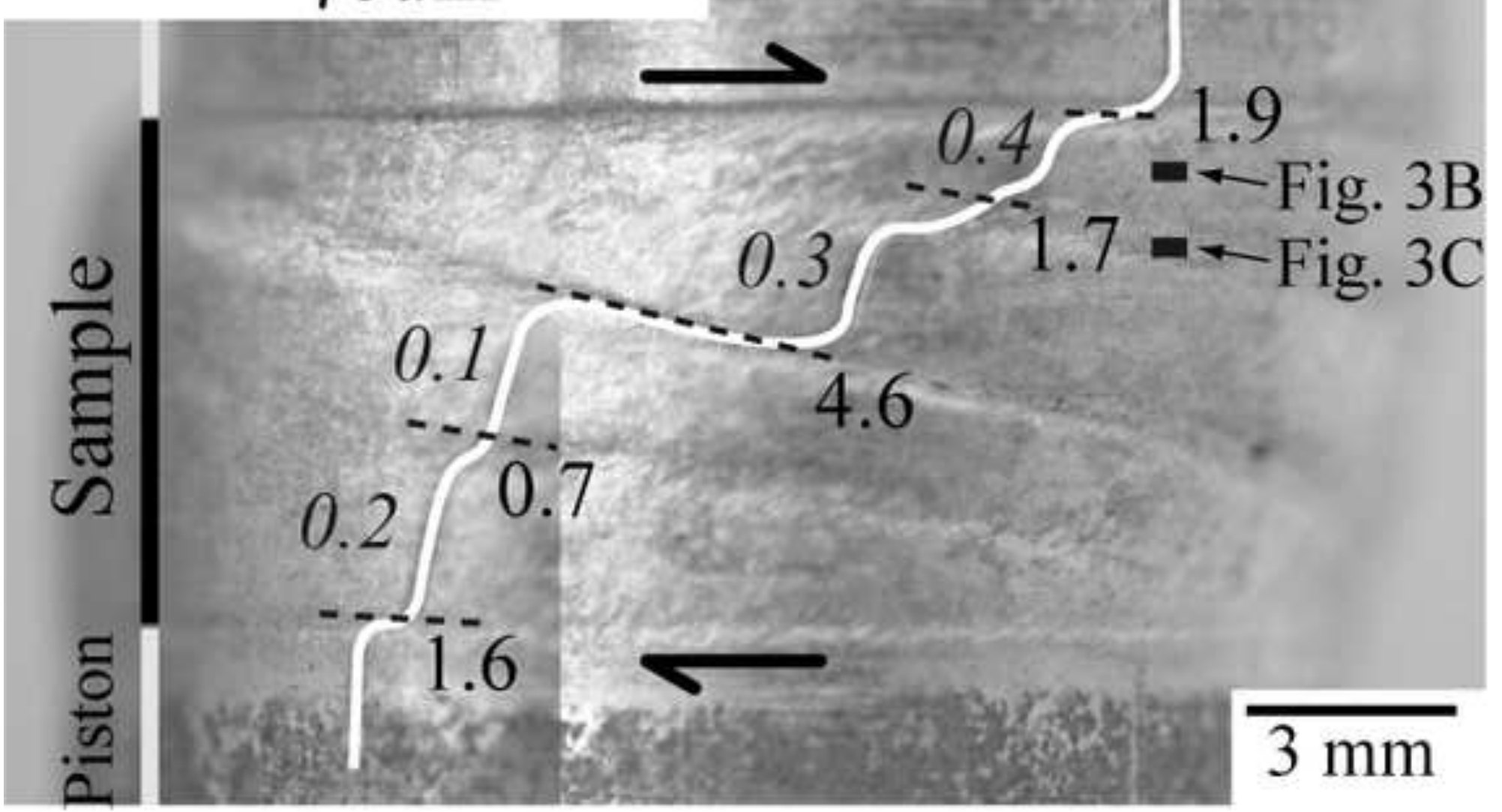

Laumonier et al., Figure1.tif 


\section{- 1column width, grey colors}

re to download high resolution image
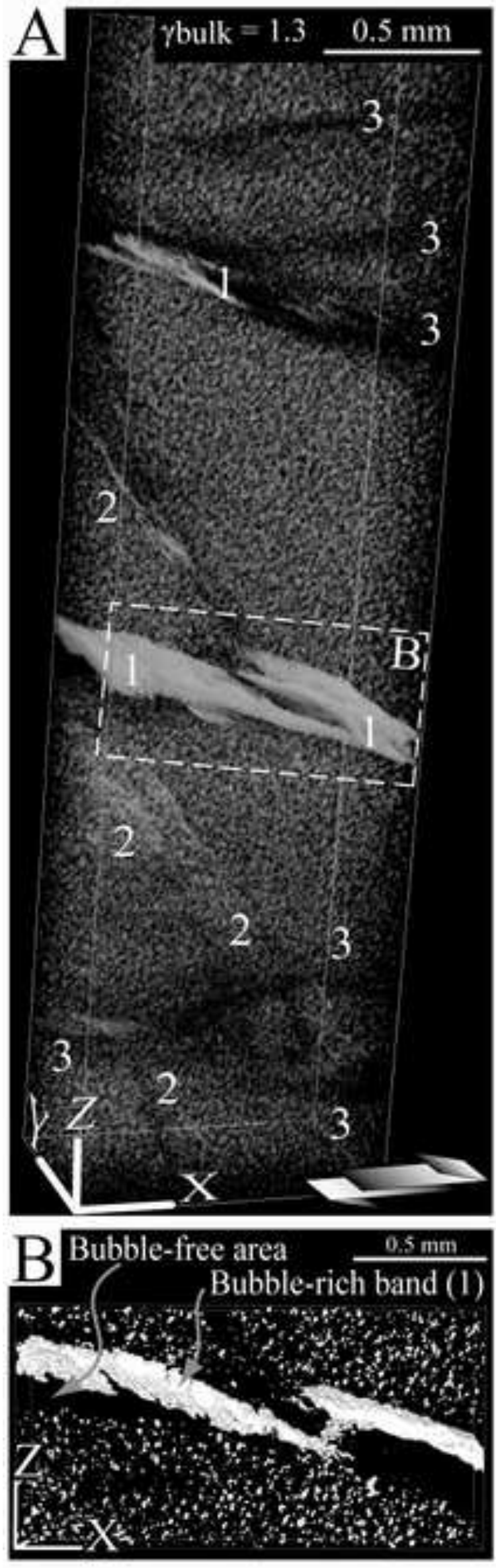

Laumonier et al., Figure2.tif 

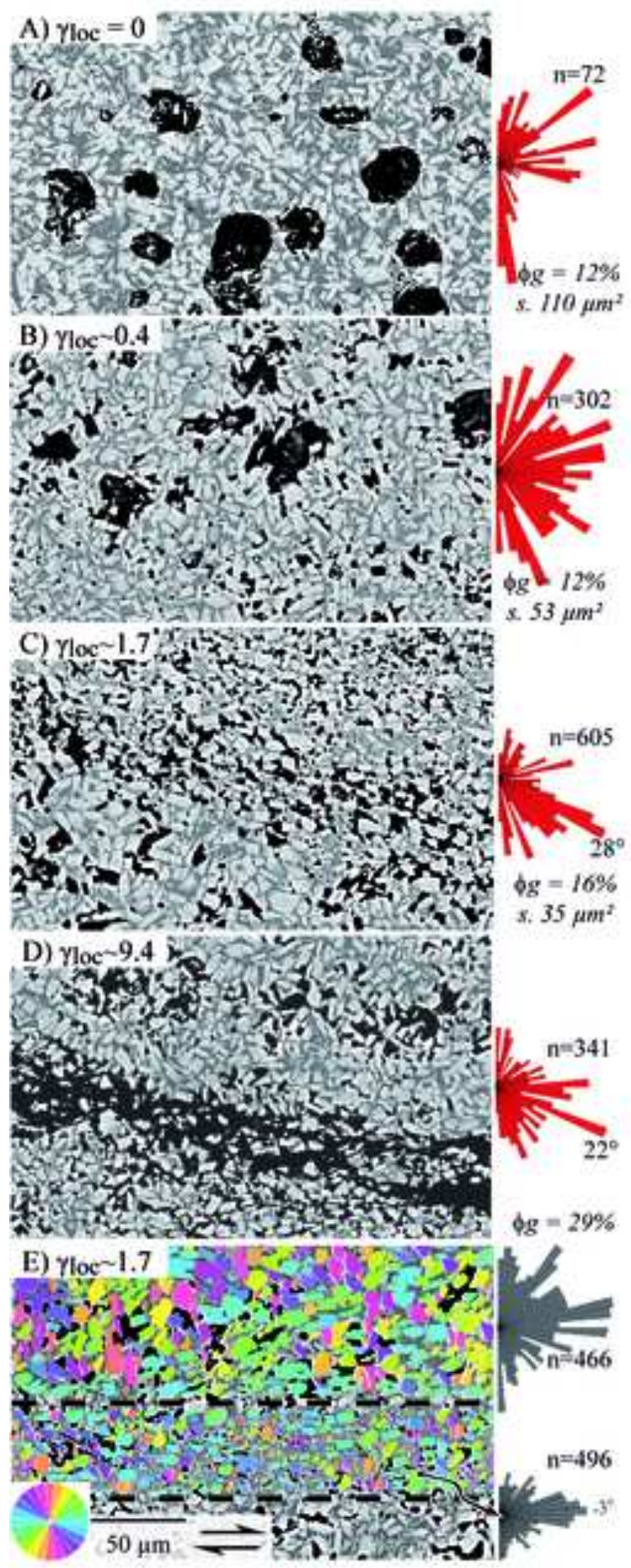

\section{Laumonier et al., Figure3.tif}


A

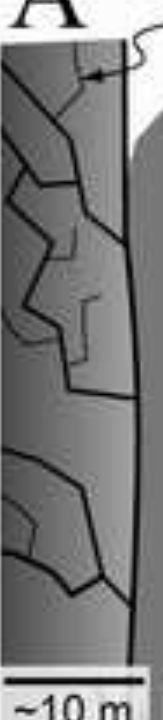

Fracture

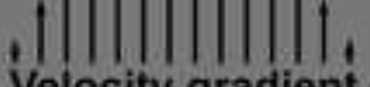

. I||||||||||,

Velocity gradient

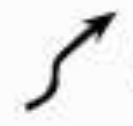

Gas circulation

$1 /$ Riedel shear $\begin{aligned} & \text { (1) } R \text { band (type 1) } \\ & \text { bands }\end{aligned} \mid \begin{aligned} & \text { (2) } R^{\prime} \text { band (type 2) } \\ & \text { (3) } P \text { band (typo 3) }\end{aligned}$

Melt

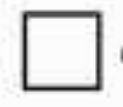

Crystals

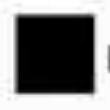

Bubbles
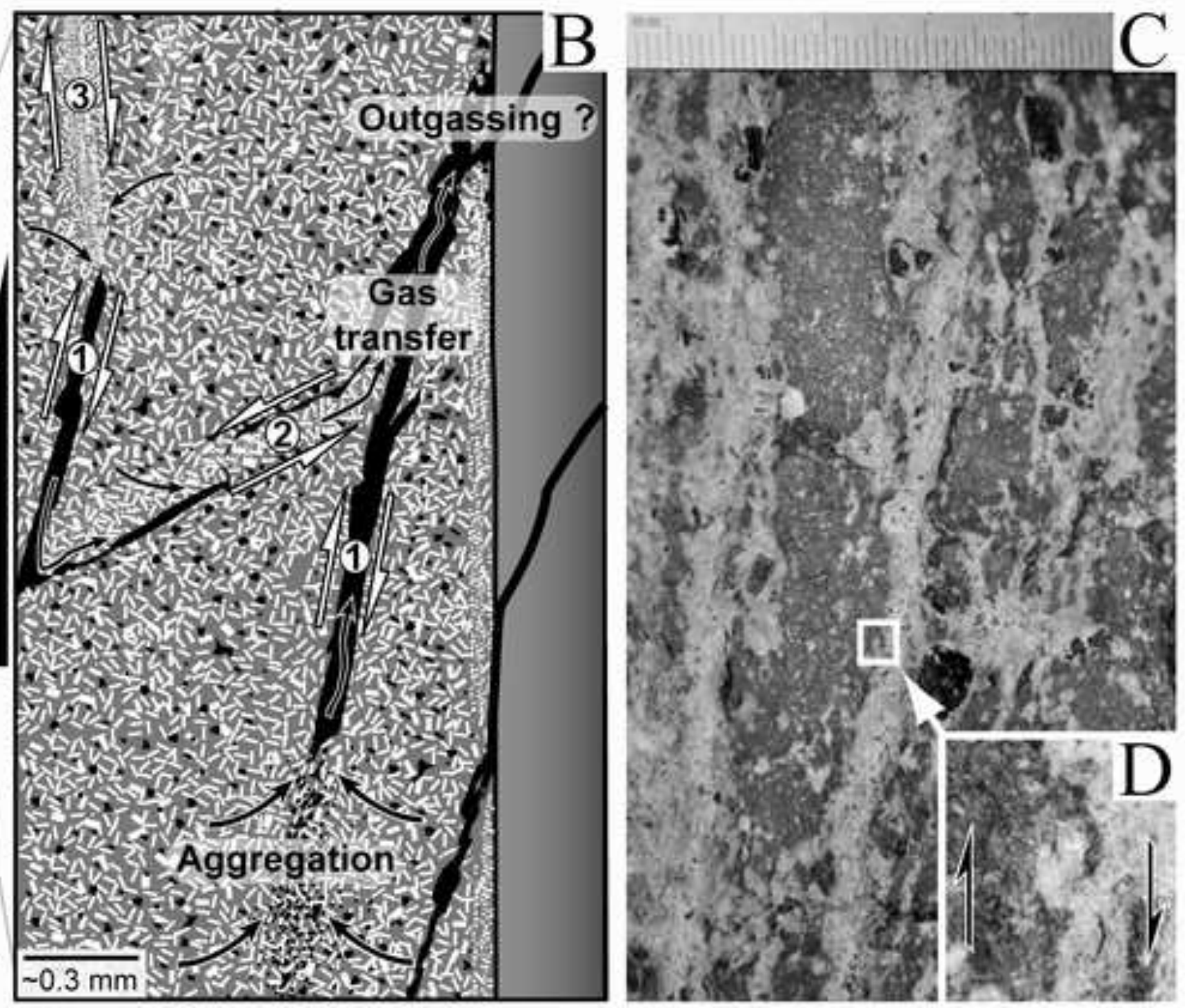

Laumonier et al., Figure4.tif 
re to download Supplemental file: supplementary file.pdf 